\title{
Risk of cardiovascular disease in inflammatory bowel disease (Review)
}

\author{
PING WU $^{1 *}$, FANGYUAN JIA $^{1 *}$, BAO ZHANG $^{1}$ and PEIYING ZHANG ${ }^{2}$ \\ Departments of ${ }^{1}$ Gastroenterology and ${ }^{2}$ Cardiology, Xuzhou Central Hospital, The Affiliated Xuzhou Hospital \\ of Medical College of Southeast University, Xuzhou, Jiangsu 221009, P.R. China
}

Received June 17, 2016; Accepted November 4, 2016

DOI: $10.3892 / \mathrm{etm} .2016 .3966$

\begin{abstract}
Cardiovascular disease (CVD) can arise because of chronic inflammation and inflammatory bowel disease (IBD) is one such disease where the risk for CVD and eventual heart failure is increased considerably. The incidence of IBD, which refers to both ulcerative colitis and Crohn's disease, has been on the increase in several countries and is a potential risk factor for CVD. Although IBD can potentially cause venous thromboembolism, its significance in arterial stiffening, atherosclerosis, ischemic heart disease and myocardial infarction is only being realized now and it is currently under debate. However, several studies with large groups of patients have demonstrated the association of IBD with heart disease. It has been suggested that systemic inflammation as observed in IBD patients leads to oxidative stress and elevated levels of inflammatory cytokines such as tumor necrosis factor- $\alpha$ (TNF- $\alpha$ ), which lead to phenotypic changes in smooth muscle cells and sets into motion a series of events that culminate in atherosclerosis and CVD. Besides the endogenous factors and cytokines, it has been suggested that due to the compromised intestinal mucosal barrier, endotoxins and bacterial lipopolysaccharides produced by intestinal microflora can enter into circulation and activate inflammatory responses that lead to atherosclerosis. Therapeutic management of IBD-associated heart diseases cannot be achieved with simple anti-inflammatory drugs such as corticosteroids and anti-TNF- $\alpha$ antibodies. Treatment with existing medications for CVDs, aspirin, platelet aggregation inhibitors and statins is found to be acceptable and safe.
\end{abstract}

Correspondence to: Dr Peiying Zhang, Department of Cardiology, Xuzhou Central Hospital, The Affiliated Xuzhou Hospital of Medical College of Southeast University, 199 Jiefang Road, Xuzhou, Jiangsu 221009, P.R. China

E-mail: zpying58@126.com

${ }^{*}$ Contributed equally

Key words: inflammatory bowel disease, cardiovascular disease, inflammation, atherosclerosis, venous thromboembolism, tumor necrosis factor- $\alpha$, endothelial cells, lipopolysaccharide, endotoxins
Nevertheless, further research is needed to assess their efficacy in IBD patients suffering from heart disease.
Contents
1. Introduction
2. IBD and arterial stiffening
3. Link between IBD and CVD
4. Role of intestinal microbiome in IBD-mediated CVD risk
5. Treatment of CVD in IBD patients
6. Conclusions

\section{Introduction}

Heart disease and failure are the major causes of mortality and morbidity worldwide, despite significant advances in medical technologies in the diagnosis and treatment of the disease. Cardiovascular disease (CVD) may arise for various reasons including the steadily increasing incidence of obesity, type 2 diabetes, genetic, environmental, dietary and lifestyle factors. Besides all these, there is much evidence suggetsing that inflammation is an important player in the pathogenesis of heart disease, as well as atherogenesis and atherosclerosis $(1,2)$. Clinically, patients with rheumatologic diseases have been found to suffer from coronary heart disease; thus, regular monitoring for CVD should be included as a routine assessment for patients with rheumatologic diseases (3). A most common systemic inflammatory disease is inflammatory bowel disease (IBD), which is a collection of ulcerative colitis and Crohn's disease, a chronic intestinal disease that may arise due to different factors, and is precipitated by environmental and genetic susceptibility (4,5). Ulcerative colitis and Crohn's disease are characterized by chronic intestinal inflammation, with gastrointestinal symptoms including diarrhea, blood and pus in stools, abdominal pain, fever and weight loss. The incidence of IBD is on the increase in Canada (6), Europe (7) and Asia (8). In ulcerative colitis, inflammation is mostly limited to mucosal layer of the colon and involves rectum and other parts of colon (9). On the other hand, Crohn's disease shows characteristic transmural inflammation and fibrosis and occurs as patchy lesions throughout the gastrointestinal tract (10). 
Although IBD is associated with venous vascular problems such as deep venous thrombosis (11), the extent of risk for the patients with IBD to develop CVD, in particular coronary artery disease is not well understood. IBD patients have a 2 to 3 -fold higher risk of venous thromboembolism than the general population (12), and this risk is high during acute disease flare, as active inflammation tilts the balance between pro-coagulants and anticoagulants, which leads to the characteristic hypofibrinolysis seen in IBD (13).

A recent meta-analysis revealed that there is a moderately elevated risk of ischemic vascular disease in patients with IBD but not peripheral arterial thromboembolic events (14). In fact, it has been observed that patients with IBD do not have a higher incidence of dyslipidemia, obesity or hypertension and yet display an elevated risk of coronary artery disease (15). Inasmuch as systemic inflammation for prolonged periods can cause platelet aggregation and endothelial dysfunction, there is a significant possibility that these events contribute to the development of atherosclerosis and CVD (16). In IBD, there is an increase in circulating inflammatory cytokines and C-reactive protein, which are known mediators of endothelial dysfunction and eventual atherosclerosis.

Arterial stiffness is known to be related to circulating levels of inflammation markers in healthy subjects, hypertensive individuals $(17,18)$, and in patients with chronic inflammatory disorders $(19,20)$. In fact, in patients with inflammatory disease for a prolonged time, the occurrence of arterial stiffening is shown to be related to the disease duration and endothelial dysfunction, but not to atherosclerosis (21). The underlying mechanisms for systemic inflammation in IBD are basically the dysfunction of the intestinal immune system and cross-reactivity against host epithelial cells (22). IBD patients have a deregulated coagulation system and when the atherosclerotic plaque ruptures, the thrombogenic core is exposed to the bloodstream, leading to thrombus formation, which causes acute coronary syndrome (23). IBD patients also have a damaged intestinal mucosal layer as some of the products from intestinal microflora find their way into blood circulation and trigger an inflammatory reaction, by activating immune and endothelial cells.

\section{IBD and arterial stiffening}

Arterial dysfunction in IBD patients is associated with the elevated production of nitric oxide, which is a known marker of inflammation (24). The relationship between systemic inflammation and arterial stiffening has been described in several conditions such as systemic vasculitis (25), systemic lupus erythematosus and rheumatoid arthritis (21). The dysfunctional endothelial system in patients with ulcerative colitis and Crohn's disease has been observed as the markers of endothelial function. Additionally, also the number of circulating endothelial precursor cells was significantly reduced in these patients, with a simultaneous increase in the number of apoptotic endothelial precursor cells (26). Recent studies have reported an increase in the stiffness of carotidfemoral arteries and the muscular arteries in IBD patients (27). There is also a significant correlation between the chronic inflammatory burden, measured as disease duration and arterial stiffness $(27,28)$. Administration of antibodies against tumor necrosis factor- $\alpha$ (TNF- $\alpha$ ) to patients with Crohn's disease was found to improve their endothelial function, albeit they did not have much effect on patients with ulcerative colitis, indicating the inflammatory mechanisms in these conditions are different (29). Further studies also demonstrated improved arterial stiffness and endothelial function in IBD patients, following anti-TNF- $\alpha$ antibody therapy, indicating the importance of this inflammatory cytokine in arterial dysfunction in IBD, which potentially leads to CVD (29-31). One of the contributory events that lead to arterial stiffening during endothelial dysfunction is the hyperplasia of vascular smooth muscle cells, in association with the elevated production of collagen (Fig. 1) (15). Furthermore, the elevated blood levels of inflammatory mediators, interleukin (IL)-1 and TNF- $\alpha$, enhance the infiltration of white blood cells into blood vessels and trigger phenotypic alterations in vascular smooth muscle cells, which release matrix metalloproteinases that break down elastin and collagen fibers, producing stiffer fragments (Fig. 1) (32). In addition, under conditions of chronic inflammation, phenotypical changes in vascular smooth muscle cells lead to the expression of osteoblast markers, resulting in an elevated uptake of phosphate and production of apatite, as well as medial calcification and reduced vessel elasticity (33). These cells also produce C-reactive protein, which plays an important role in curtailing endothelial function and promoting vascular inflammation.

\section{Link between IBD and CVD}

As mentioned above, the prevalence of classical cardiovascular risk factors, including body mass index, lipidemia, incidence of diabetes, obesity and hypertension, is relatively lower in IBD patients than in the general population $(34,35)$. However, the risk of coronary heart disease is higher in IBD patients $(36,37)$. Although IBD patients likely suffer from venous thromboembolic events and the needed clinical precautions are in place (12), such is not the case for the possible arterial thromboembolic events in these patients, as this matter is under debate. In 2000, a large registry-based Canadian study with 8,060 IBD patients showed a $26 \%$ increased risk of ischemic heart disease, as compared to non-IBD patients, with women being at higher risk (38). These results were mostly confirmed in other studies $(36,39)$. A large nationwide study conducted in Denmark that examined the risk of coronary heart disease in 28,833 patients with IBD as compared to $>4.5$ million individuals without IBD with a mean follow-up for $\sim 13$ years, concluded that the incidence of coronary heart disease is 59\% higher in IBD patients, after adjusting for all the confounding factors (40). Notably, the same cohort of patients also suffered increased risk of stroke (41) and risk of hospitalization due to heart failure (42). However, such risk was not identified in other studies (43). Additionally, it was suggested that the discrepant results can be due to patient selection bias and inclusion of more severely ill patients. Although a strong association between IBD and increased risk of acute myocardial infarction was observed in a UK study of 15,498 patients, this association was lost after making adjustment for potential confounders such as age, gender, hypertension and diabetes (44). Again, such adjustment may have caused skewing of the data to include a 


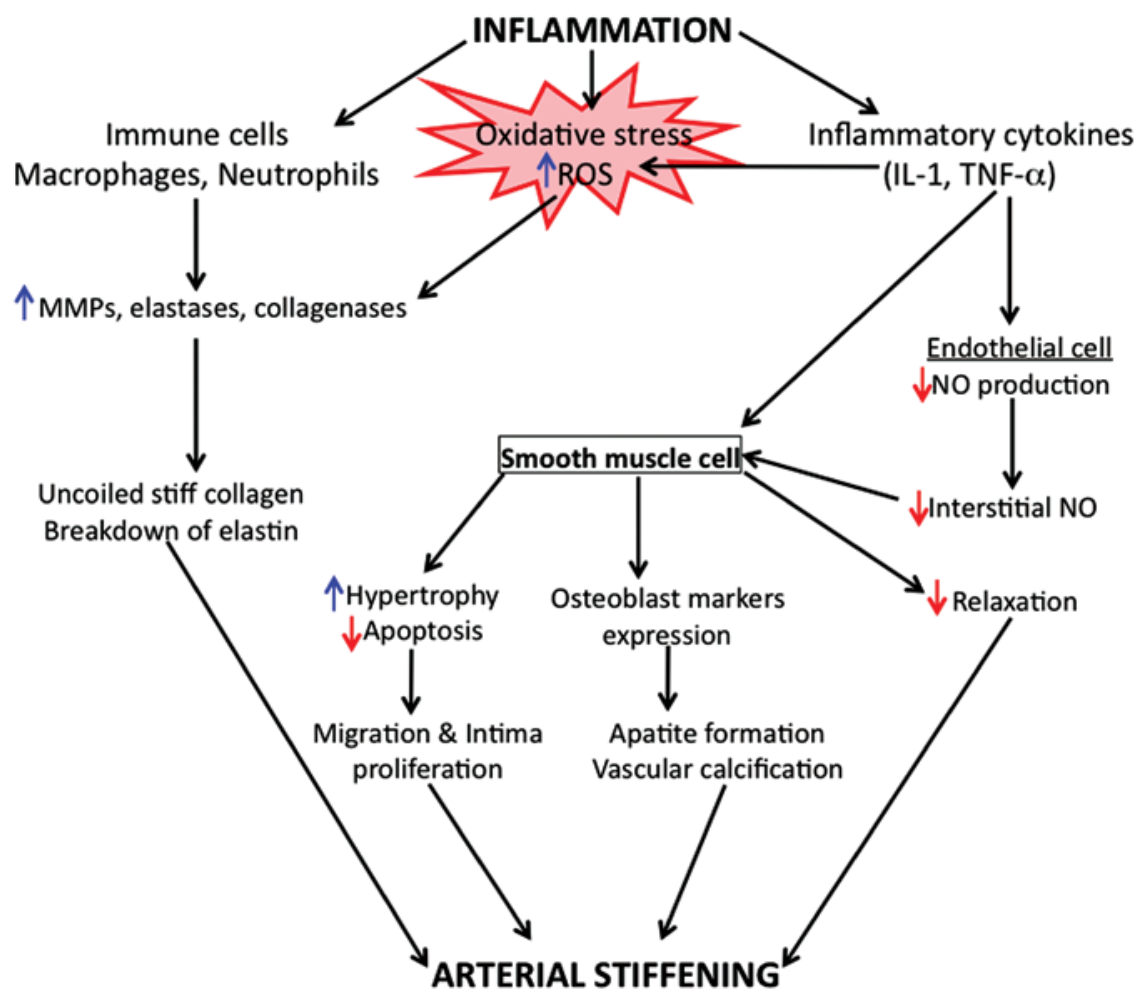

Figure 1. Mechanisms underlying the inflammation-induced arterial stiffening. Inflammation triggers oxidative stress and release and elevation of inflammatory cytokines including tumor necrosis factor- $\alpha(\mathrm{TNF}-\alpha)$. These changes lead to endothelial dysfunction, reduced nitric oxide (NO) production, elevated production of matrix metalloproteinases (MMPs), collagenase, elastases, all leading to arterial stiffening. Reduced level of NO contributes to decreased smooth muscle cell relaxation and TNF- $\alpha$ signaling induces the expression of osteoblast markers in smooth muscle cells, leading to calcification changes and intima thickening.

less severe IBD patient population and introduced a selection bias (45). The majority of studies indicate a modestly elevated risk of heart disease in IBD patients, with women being at higher risk. It should also be mentioned that while there is an elevated risk for heart disease, there is no increase in CVD-related mortality in IBD patients. Significant advances in therapeutic modalities in treating CVD has led to a great decline in CVD-related mortalities, although these numbers do not match well with CVD-related morbidity (46).

The elevated levels of inflammatory cytokines in IBD can cause the endothelium-dependent dilatation of arteries and thus promote atherosclerosis (Fig. 2) (47). In fact, atherosclerosis is being increasingly considered as a chronic inflammatory disease, with the infiltration of several types of immune cells into the arterial wall, in response to signals produced by activated endothelial cells (48). A major contributor for this is the C-reactive protein, which is increased several fold in IBD patients and which is a predictive marker for CVD (29,49). Among the other inflammatory mediators, TNF- $\alpha$, vascular endothelial growth factor (VEGF) and IL-6 also play a role in promoting CVD risk in IBD patients. For example, VEGF, which promotes vessel formation, is known to increase angiogenesis and inflammation and thereby worsens atherosclerosis in IBD patients $(50,51)$. Other associated factors that correlate with IBD include abnormal number, size and density of platelets, which regulate a number of inflammatory responses (52). It has been observed that production of an acute phase reactant calprotectin by neutrophils, is elevated in IBD and increased levels of calprotectin are predictive of CVD (53).

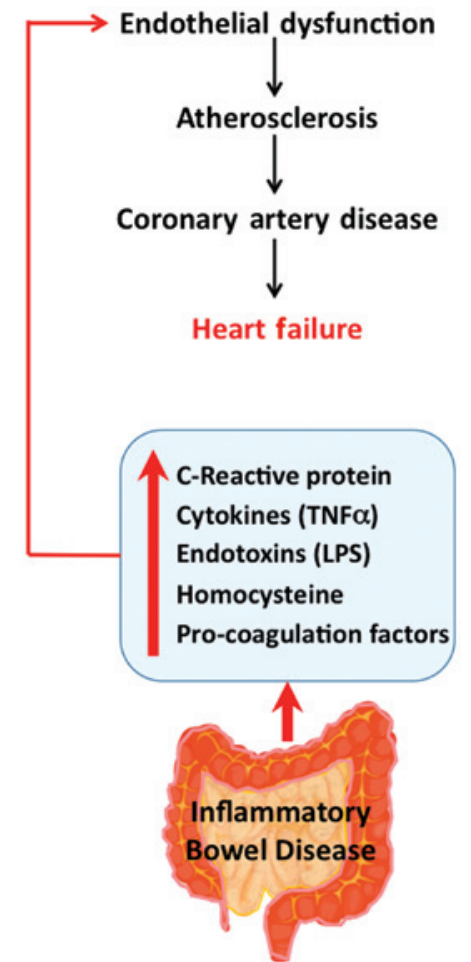

Figure 2. Link between inflammatory bowel diseases (IBD) and coronary artery disease. Cytokines and C-reactive protein are elevated in IBD and promote atherosclerosis and cardiovascular disease through endothelial dysfunction. Hyperhomocysteinemia is another potential link between IBD and CVD. Intestinal microflora produced endotoxins including lipopolysaccharide (LPS), which cross through the leaky intestinal mucosal barrier, activate immune cells and endothelial cells, and promote events that culminate in atherosclerosis. 


\section{Role of intestinal microbiome in IBD-mediated CVD risk}

Besides the mediators of inflammation produced locally by the endogenous sources, the importance of endotoxins and microbial products from intestine has recently gathered much attention. It has been recognized that the disrupted intestinal mucosal barrier in IBD facilitates the translocation of microbial lipopolysaccharides (LPS) and other endotoxins into circulation. Thus, elevated levels of LPS have been described in IBD patients and correlate with disease activity (54). It is well known that LPS is highly inflammatory and induces the expression of proinflammatory cytokines, which in turn cause endothelial damage and foam cell formation (55) and eventually lead to atherosclerosis (56). LPS has many detrimental effects including oxidation of low-density lipoproteins (57), which are toxic for endothelial cells (58) and activation of macrophages, which increase atherosclerosis (Fig. 2) (59).

At the molecular level, it has been suggested that the increased expression of Toll-like receptors 2 and 4 (TLR2 and 4) in inflammatory cells (e.g., monocytes) likely mediate the damaging signaling events triggered by LPS and other microbial toxins and in fact, elevated levels of TLR2 and 4 have been observed in atherosclerotic plaques (60). In isolated monocytes from IBD patients, the addition of TLR2 agonists led to the elevated production and release of TNF- $\alpha$, as compared to monocytes from healthy subjects, indicating an elevated expression/signaling of TLR2 in IBD patient monocytes (61). Even though TLR4 polymorphism has been suggested to be associated with disease state in IBD patients, this has not been confirmed in other studies and more research is needed to ascertain such a relationship $(62,63)$. It has also been observed that in IBD patients, the blood levels of homocysteine are greatly elevated (64) and inasmuch as homocysteine induces oxidative stress, reduces nitric oxide levels and causes endothelial dysfunction, it constitutes a major risk factor for atherogenic plaque formation (65). The incidence of hyperhomocysteinemia is 4 - to 5 -fold higher in IBD patients than in control subjects (66), emphasizing the importance of this factor in the development of atherosclerosis and associated coronary heart disease.

\section{Treatment of CVD in IBD patients}

Therapy of IBD may reduce the risk of CVD incidence, but such observational studies are limited and some of the anti-inflammatory drugs may elevate the risk of CVD. Corticosteroids, for example, have been associated with elevated cardiovascular events in IBD patients (40). However, corticosteroids when taken at high doses are known to increase cardiovascular events in the general population as well. In the same cohort, it was also reported that the use of an inhibitor of platelet activation, 5-aminosalysylate, is associated with reduced inflammation and decreased cardiovascular events. Epidemiological studies have not revealed any significant improvement in CVD outcomes in patients treated with immunomodulators (41). Use of anti-TNF medications did not show beneficial effects in IBD patients. even though they were effective in lowering CVD risk in patients with rheumatoloid arthritis (46).
Use of previously accepted medications for CVDs such as aspirin, anti-platelet agent clopidogrel, and statins is suggested to be safe for reducing CVD risk in IBD patients. However, further investigation is needed to assess their efficacy.

\section{Conclusions}

Chronic IBD poses a risk for CVD and eventual heart failure. The incidence of IBD (consisting of both ulcerative colitis and Crohn's disease), is on the increase worldwide and thus is a potential risk factor for CVD. The significance of IBD in causing arterial stiffening, atherosclerosis and ischemic heart disease and myocardial infarction is currently being recognized. Systemic inflammation in IBD patients leads to oxidative stress and elevated levels of inflammatory cytokines such as TNF- $\alpha$, leading to phenotypic changes in smooth muscle cells that culminate in atherosclerosis and CVD. It has also been suggested that, endotoxins and bacterial LPS produced by intestinal microflora can enter the circulation, due to the leaky intestinal mucosal barrier and contribute to inflammatory responses that lead to atherosclerosis. IBD-associated heart diseases are not treated effectively with anti-inflammatory drugs such as corticosteroids and anti-TNF- $\alpha$ antibodies. Additionally, existing medications for CVD, including aspirin, platelet aggregation inhibitors and statins, are considered acceptable and safe.

\section{References}

1. Matsuura E, Atzeni F, Sarzi-Puttini P, Turiel M, Lopez LR and Nurmohamed MT: Is atherosclerosis an autoimmune disease? BMC Med 12: 47, 2014.

2. Libby P, Lichtman AH and Hansson GK: Immune effector mechanisms implicated in atherosclerosis: from mice to humans. Immunity 38: 1092-1104, 2013.

3. Prasad M, Hermann J, Gabriel SE, Weyand CM, Mulvagh S, Mankad R, Oh JK, Matteson EL and Lerman A: Cardiorheumatology: cardiac involvement in systemic rheumatic disease. Nat Rev Cardiol 12: 168-176, 2015.

4. Conrad K, Roggenbuck D and Laass MW: Diagnosis and classification of ulcerative colitis. Autoimmun Rev 13: 463-466, 2014.

5. Laass MW, Roggenbuck D and Conrad K: Diagnosis and classification of Crohn's disease. Autoimmun Rev 13: 467-471, 2014.

6. Bernstein CN, Wajda A, Svenson LW, MacKenzie A, Koehoorn M, Jackson M, Fedorak R, Israel D and Blanchard JF: The epidemiology of inflammatory bowel disease in Canada: a population-based study. Am J Gastroenterol 101: 1559-1568, 2006.

7. Burisch J, Jess T, Martinato M and Lakatos PL; ECCO-EpiCom: The burden of inflammatory bowel disease in Europe. J Crohns Colitis 7: 322-337, 2013.

8. Ng SC: Epidemiology of inflammatory bowel disease: focus on Asia. Best Pract Res Clin Gastroenterol 28: 363-372, 2014.

9. Danese S and Fiocchi C: Ulcerative colitis. N Engl J Med 365: 1713-1725, 2011.

10. Baumgart DC and Sandborn WJ: Crohn's disease. Lancet 380: 1590-1605, 2012.

11. Tan VP, Chung A, Yan BP and Gibson PR: Venous and arterial disease in inflammatory bowel disease. J Gastroenterol Hepatol 28: 1095-1113, 2013.

12. Nguyen GC, Bernstein CN, Bitton A, Chan AK, Griffiths AM, Leontiadis GI, Geerts W, Bressler B, Butzner JD, Carrier M, et al: Consensus statements on the risk, prevention, and treatment of venous thromboembolism in inflammatory bowel disease: Canadian Association of Gastroenterology. Gastroenterology 146: 835-848, 2014.

13. Grainge MJ, West J and Card TR: Venous thromboembolism during active disease and remission in inflammatory bowel disease: a cohort study. Lancet 375: 657-663, 2010. 
14. Singh S, Singh H, Loftus EV Jr and Pardi DS: Risk of cerebrovascular accidents and ischemic heart disease in patients with inflammatory bowel disease: a systematic review and meta-analysis. Clin Gastroenterol Hepatol 12: 382-393, 2014.

15. Zanoli L, Rastelli S, Inserra G and Castellino P: Arterial structure and function in inflammatory bowel disease. World J Gastroenterol 21: 11304-11311, 2015.

16. Hansson GK: Inflammation, atherosclerosis, and coronary artery disease. N Engl J Med 352: 1685-1695, 2005.

17. Pietri P, Vyssoulis G, Vlachopoulos C, Zervoudaki A, Gialernios T, Aznaouridis K and Stefanadis C: Relationship between low-grade inflammation and arterial stiffness in patients with essential hypertension. J Hypertens 24: 2231-2238, 2006.

18. Yasmin, McEniery CM, Wallace S, Mackenzie IS, Cockcroft JR and Wilkinson IB: C-reactive protein is associated with arterial stiffness in apparently healthy individuals. Arterioscler Thromb Vasc Biol 24: 969-974, 2004.

19. Mäki-Petäjä KM, Hall FC, Booth AD, Wallace SM, Yasmin, Bearcroft PW, Harish S, Furlong A, McEniery CM, Brown J, et al: Rheumatoid arthritis is associated with increased aortic pulse-wave velocity, which is reduced by anti-tumor necrosis factor-alpha therapy. Circulation 114: 1185-1192, 2006.

20. Schillaci G, De Socio GV, Pucci G, Mannarino MR, Helou J Pirro M and Mannarino E: Aortic stiffness in untreated adult patients with human immunodeficiency virus infection. Hypertension 52: 308-313, 2008.

21. Roman MJ, Devereux RB, Schwartz JE, Lockshin MD, Paget SA, Davis A, Crow MK, Sammaritano L, Levine DM, Shankar BA, et al: Arterial stiffness in chronic inflammatory diseases. Hypertension 46: 194-199, 2005.

22. Yu Y, Sitaraman S and Gewirtz AT: Intestinal epithelial cell regulation of mucosal inflammation. Immunol Res 29 : 55-68, 2004.

23. Scaldaferri F, Lancellotti S, Pizzoferrato M and De Cristofaro R Haemostatic system in inflammatory bowel diseases: new players in gut inflammation. World J Gastroenterol 17: 594-608 2011.

24. Horowitz S, Binion DG, Nelson VM, Kanaa Y, Javadi P, Lazarova Z, Andrekopoulos C, Kalyanaraman B, Otterson MF and Rafiee P: Increased arginase activity and endothelial dysfunction in human inflammatory bowel disease. Am J Physio Gastrointest Liver Physiol 292: G1323-G1336, 2007.

25. Booth AD, Wallace S, McEniery CM, Yasmin, Brown J, Jayne DR and Wilkinson IB: Inflammation and arterial stiffness in systemic vasculitis: a model of vascular inflammation. Arthritis Rheum 50: 581-588, 2004

26. Garolla A, D'Incà R, Checchin D, Biagioli A, De Toni L, Nicoletti V, Scarpa M, Bolzonello E, Sturniolo GC and Foresta C: Reduced endothelial progenitor cell number and function in inflammatory bowel disease: a possible link to the pathogenesis. Am J Gastroenterol 104: 2500-2507, 2009.

27. Zanoli L, Rastelli S, Inserra G, Lentini P, Valvo E, Calcagno E, Boutouyrie P, Laurent S and Castellino P: Increased arterial stiffness in inflammatory bowel diseases is dependent upon inflammation and reduced by immunomodulatory drugs. Atherosclerosis 234: 346-351, 2014.

28. Zanoli L, Cannavò M, Rastelli S, Di Pino L, Monte I, Di Gangi M, Boutouyrie P, Inserra G, Laurent S and Castellino P: Arterial stiffness is increased in patients with inflammatory bowel disease. J Hypertens 30: 1775-1781, 2012.

29. Schinzari F, Armuzzi A, De Pascalis B, Mores N, Tesauro M, Melina D and Cardillo C: Tumor necrosis factor-alpha antagonism improves endothelial dysfunction in patients with Crohn's disease. Clin Pharmacol Ther 83: 70-76, 2008.

30. Theocharidou E, Mavroudi M, Soufleris K, Griva T, Giouleme O, Athyros VG and Karagiannis A: Aortic stiffness in patients with inflammatory bowel diseases. Hell J Atherosclerosis 4 : 200-207, 2013

31. Theocharidou E, Tellis CC, Mavroudi M, Soufleris K, Gossios TD, Giouleme O, Athyros VG, Tselepis AD and Karagiannis A: Lipoprotein-associated phospholipase A2 and arterial stiffness evaluation in patients with inflammatory bowel diseases. J Crohns Colitis 8: 936-944, 2014.

32. Zieman SJ, Melenovsky V and Kass DA: Mechanisms, pathophysiology, and therapy of arterial stiffness. Arterioscler Thromb Vasc Biol 25: 932-943, 2005.

33. Floege $\mathbf{J}$ and Ketteler M: Vascular calcification in patients with end-stage renal disease. Nephrol Dial Transplant 19 (Suppl 5): V59-V66, 2004.
34. Geerling BJ, Badart-Smook A, Stockbrügger RW and Brummer RJ: Comprehensive nutritional status in recently diagnosed patients with inflammatory bowel disease compared with population controls. Eur J Clin Nutr 54: 514-521, 2000

35. Jahnsen J, Falch JA, Mowinckel P and Aadland E: Body composition in patients with inflammatory bowel disease: a population-based study. Am J Gastroenterol 98: 1556-1562,2003.

36. Yarur AJ, Deshpande AR, Pechman DM, Tamariz L, Abreu MT and Sussman DA: Inflammatory bowel disease is associated with an increased incidence of cardiovascular events. Am J Gastroenterol 106: 741-747, 2011.

37. Haapamäki J, Roine RP, Turunen U, Färkkilä MA and Arkkila PE: Increased risk for coronary heart disease, asthma, and connective tissue diseases in inflammatory bowel disease. J Crohns Colitis 5: 41-47, 2011

38. Bernstein CN, Wajda A and Blanchard JF: The incidence of arterial thromboembolic diseases in inflammatory bowel disease: a population-based study. Clin Gastroenterol Hepatol 6: 41-45, 2008.

39. Ha C, Magowan S, Accortt NA, Chen J and Stone CD: Risk of arterial thrombotic events in inflammatory bowel disease. Am J Gastroenterol 104: 1445-1451, 2009.

40. Rungoe C, Basit S, Ranthe MF, Wohlfahrt J, Langholz E and Jess T: Risk of ischaemic heart disease in patients with inflammatory bowel disease: a nationwide Danish cohort study. Gut 62 689-694, 2013.

41. Kristensen SL, Ahlehoff O, Lindhardsen J, Erichsen R, Jensen GV, Torp-Pedersen C, Nielsen OH, Gislason GH and Hansen PR: Disease activity in inflammatory bowel disease is associated with increased risk of myocardial infarction, stroke and cardiovascular death - a Danish nationwide cohort study. PLoS One 8: e56944, 2013.

42. Kristensen SL, Ahlehoff O, Lindhardsen J, Erichsen R, Lamberts M, Khalid U, Nielsen $\mathrm{OH}$, Torp-Pedersen $\mathrm{C}$, Gislason GH and Hansen PR: Inflammatory bowel disease is associated with an increased risk of hospitalization for heart failure: a Danish Nationwide Cohort study. Circ Heart Fail 7: 717-722, 2014.

43. Sridhar AR, Parasa S, Navaneethan U, Crowell MD and Olden K: Comprehensive study of cardiovascular morbidity in hospitalized inflammatory bowel disease patients. J Crohns Colitis 5: 287-294, 2011.

44. Osterman MT, Yang YX, Brensinger C, Forde KA, Lichtenstein GR and Lewis JD: No increased risk of myocardial infarction among patients with ulcerative colitis or Crohn's disease. Clin Gastroenterol Hepatol 9: 875-880, 2011.

45. Rungoe C, Nyboe Andersen $\mathrm{N}$ and Jess T: Inflammatory bowel disease and risk of coronary heart disease. Trends Cardiovasc Med 5: 699-704, 2015

46. Singh S, Kullo IJ, Pardi DS and Loftus EV Jr: Epidemiology, risk factors and management of cardiovascular diseases in IBD. Nat Rev Gastroenterol Hepatol 12: 26-35, 2015.

47. Hingorani AD, Cross J, Kharbanda RK, Mullen MJ, Bhagat K, Taylor M, Donald AE, Palacios M, Griffin GE, Deanfield JE, et al: Acute systemic inflammation impairs endothelium-dependent dilatation in humans. Circulation 102: 994-999, 2000

48. Lusis AJ: Atherosclerosis. Nature 407: 233-241, 2000.

49. Ridker PM, Danielson E, Fonseca FA, Genest J, Gotto AM Jr, Kastelein JJ, Koenig W, Libby P, Lorenzatti AJ, MacFadyen JG, et al; JUPITER Study Group: Rosuvastatin to prevent vascular events in men and women with elevated C-reactive protein. N Engl J Med 359: 2195-2207, 2008.

50. Scaldaferri F, Vetrano S, Sans M, Arena V, Straface G, Stigliano E, Repici A, Sturm A, Malesci A, Panes J, et al: VEGF-A links angiogenesis and inflammation in inflammatory bowel disease pathogenesis. Gastroenterology 136: 585-595, 2009.

51. Testa U, Pannitteri G and Condorelli GL: Vascular endothelial growth factors in cardiovascular medicine. J Cardiovasc Med (Hagerstown) 9: 1190-1221, 2008.

52. Danese S, Motte Cd CL and Fiocchi C: Platelets in inflammatory bowel disease: clinical, pathogenic, and therapeutic implications. Am J Gastroenterol 99: 938-945, 2004.

53. Jensen LJ, Pedersen S, Bjerre M, Mogelvang R, Jensen JS and Flyvbjerg A: Plasma calprotectin predicts mortality in patients with ST segment elevation myocardial infarction treated with primary percutaneous coronary intervention. J Interv Cardiol 23: 123-129, 2010.

54. McDonnell M, Liang Y, Noronha A, Coukos J, Kasper DL, Farraye FA and Ganley-Leal LM: Systemic Toll-like receptor ligands modify B-cell responses in human inflammatory bowel disease. Inflamm Bowel Dis 17: 298-307, 2011. 
55. Howell KW, Meng X, Fullerton DA, Jin C, Reece TB and Cleveland JC Jr: Toll-like receptor 4 mediates oxidized LDL-induced macrophage differentiation to foam cells. J Surg Res 171: e27-e31, 2011.

56. Wiedermann CJ, Kiechl S, Dunzendorfer S, Schratzberger P, Egger G, Oberhollenzer F and Willeit J: Association of endotoxemia with carotid atherosclerosis and cardiovascular disease: prospective results from the Bruneck Study. J Am Coll Cardiol 34: 1975-1981, 1999.

57. Maziere C, Conte MA, Dantin F and Maziere JC: Lipopolysaccharide enhances oxidative modification of low density lipoprotein by copper ions, endothelial and smooth muscle cells. Atherosclerosis 143: 75-80, 1999.

58. Morel DW, DiCorleto PE and Chisolm GM: Modulation of endotoxin-induced endothelial cell toxicity by low density lipoprotein. Lab Invest 55: 419-426, 1986.

59. Wiesner P, Choi SH, Almazan F, Benner C, Huang W, Diehl CJ, Gonen A, Butler S, Witztum JL, Glass CK, et al: Low doses of lipopolysaccharide and minimally oxidized low-density lipoprotein cooperatively activate macrophages via nuclear factor kappa B and activator protein-1: Possible mechanism for acceleration of atherosclerosis by subclinical endotoxemia. Circ Res 107: 56-65, 2010.
60. Edfeldt K, Swedenborg J, Hansson GK and Yan ZQ: Expression of toll-like receptors in human atherosclerotic lesions: a possible pathway for plaque activation. Circulation 105: 1158$1161,2002$.

61. Cantó E, Ricart E, Monfort D, González-Juan D, Balanzó J, Rodríguez-Sánchez JL and Vidal S: TNF alpha production to TLR2 ligands in active IBD patients. Clin Immunol 119: $156-165,2006$

62. Kiechl S, Lorenz E, Reindl M, Wiedermann CJ, Oberhollenzer F, Bonora E, Willeit J and Schwartz DA: Toll-like receptor 4 polymorphisms and atherogenesis. N Engl J Med 347: 185-192, 2002.

63. Labrum R, Bevan S, Sitzer M, Lorenz M and Markus HS: Toll receptor polymorphisms and carotid artery intima-media thickness. Stroke 38: 1179-1184, 2007.

64. Oussalah A, Guéant JL and Peyrin-Biroulet L: Meta-analysis: hyperhomocysteinaemia in inflammatory bowel diseases. Aliment Pharmacol Ther 34: 1173-1184, 2011.

65. Hankey GJ and Eikelboom JW: Homocysteine and vascular disease. Lancet 354: 407-413, 1999.

66. Drzewoski J, Gasiorowska A, Małecka-Panas E, Bald E and Czupryniak L: Plasma total homocysteine in the active stage of ulcerative colitis. J Gastroenterol Hepatol 21: 739-743, 2006. 